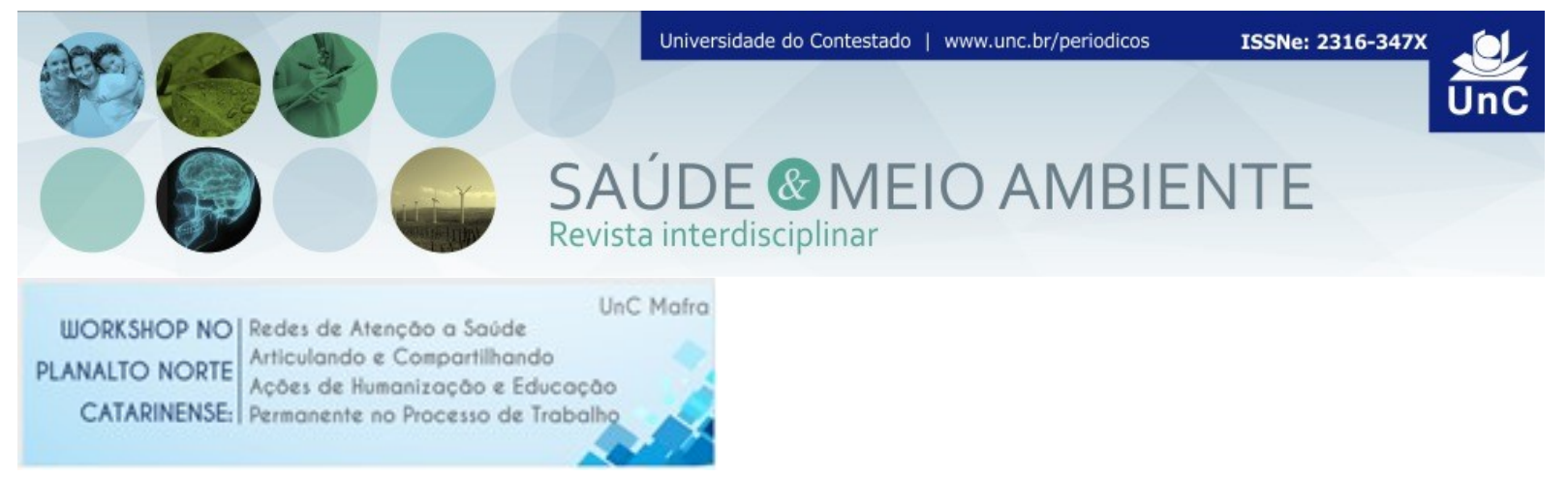

\title{
CAPACITAÇÃO DOS PROFISSIONAIS DA ATENÇÃO PRIMÁRIA À SAÚDE DE SÃO BENTO DO SUL/SC SOBRE O SUICÍDIO EM ADOLESCENTES: AÇÕES DO SETEMBRO AMARELO ${ }^{1}$
}

\author{
Ricardo Larroyed de Oliveira ${ }^{2}$ \\ Elisabeth Maria Nardelli de Oliveira ${ }^{3}$ \\ Cristiane Aparecida Jantsch Sestren ${ }^{4}$ \\ Carin Luciane Denk Tschoke ${ }^{5}$
}

\section{RESUMO}

INTRODUÇÃO: O suicídio é um problema frequente no Brasil e no mundo, com aumento progressivo do número de ocorrências nas últimas décadas, especialmente entre jovens (CALIXTO; ZERBINI, 2017). O alto índice de suicídio na adolescência reflete a maior fragilidade nessa fase do desenvolvimento, onde podem ocorrer sentimentos intensos de baixa autoestima e transtornos psiquiátricos graves (BORGES; WERLANG, 2006). A prevenção do suicídio em jovens requer o uso de múltiplas estratégias, como a detecção precoce do comportamento suicida e o tratamento adequado (BAGGIO; PALAZZO; AERTS, 2009). Neste contexto, a Atenção Primária à Saúde (APS) pode exercer um papel estratégico, devido ao seu maior vínculo com a comunidade, na prevenção do suicídio (OMS, 2000). OBJETIVOS: Capacitar os profissionais da Atenção Primária à Saúde de São Bento do Sul/SC para a identificação, abordagem, manejo e encaminhamento de adolescentes com risco de suicídio na comunidade. RELATO DE EXPERIÊNCIA: Foram conduzidas por um médico e uma psicóloga, familiarizados com o tema do suicídio, cinco oficinas ativas participativas, com média de 40 participantes cada e com duração estimada de 3 horas e trinta minutos. Esses encontros tiveram como base o diálogo constante e a troca de experiências, de forma a estimular a reflexão, abrindo um espaço real de participação e construção de um novo olhar sobre a atuação das equipes na questão do suicídio em adolescentes. Foi utilizado como material de referência a publicação da OMS (2000): "Prevenção do suicídio: um manual para profissionais da saúde em atenção primária". Cada oficina foi organizada em seis momentos: 1) Apresentação (15 minutos): abertura e apresentação dos objetivos da oficina; levantamento das

1Financiamento: Secretaria Municipal de Saúde de São Bento do Sul/SC

2 Médico, Prefeitura Municipal de São Bento do Sul. Santa Catarina. Brasil. E-mail: ricardo oliveira@saobentodosul.sc.gov.br

${ }^{3}$ Psicóloga, Prefeitura Municipal de São Bento do Sul. Santa Catarina. Brasil. E-mail: elisabeth@saobentodosul.sc.gov.br

${ }^{4}$ Enfermeira, Prefeitura Municipal de São Bento do Sul. Santa Catarina. Brasil. E-mail: cristiane sestren@saobentodosul.sc.gov.br

${ }^{5}$ Farmacêutica, Prefeitura Municipal de São Bento do Sul. Santa Catarina. Brasil. E-mail: dstaids@saobentodosul.sc.gov.br 
expectativas dos participantes; distribuição dos materiais e leitura da programação da oficina; elaboração do acordo de convivência. 2) Unidade Didática I (2 horas): contextualização do suicídio como problema de saúde pública; sensibilização para a importância da prevenção do suicídio; exposição sobre os fatores de proteção e risco para o suicídio; identificação e abordagem de pessoas em risco de suicídio e manejo da pessoa de acordo com grau de risco de suicídio; apresentação e uso do fluxograma de atendimento as pessoas com risco de suicídio na Rede de Atenção à Saúde Mental de São Bento do Sul/SC. 3) Intervalo (15 minutos). 4) Unidade Didática II (15 minutos): notificação dos casos de violência interpessoal. 5) Discussão de casos (1 hora): exposição e discussão de quatro casos clínicos envolvendo adolescentes com diferentes riscos de suicídio. 6) Encerramento e avaliação da oficina por meio do formulário padronizado de avaliação de atividades educativas do Núcleo de Educação Permanente de São Bento do Sul (NEP/SBS). RESULTADOS: O preenchimento do formulário de avaliação de atividades educativas do NEP/SBS era voluntário e, dos cerca de 200 participantes de todas as oficinas, $178(89 \%)$ o preencheram. Os horários das oficinas (predominantemente a tarde) foram avaliados como ótimos ou bons por $91,6 \%$ dos participantes. A escolha dos palestrantes foi considerada ótima ou boa por $98,8 \%$. O andamento da apresentação foi avaliado como ótimo ou bom por $96 \%$. A apresentação do tema pelos palestrantes foi avaliada como ótima ou boa por $98 \%$. Cerca de $96,6 \%$ dos participantes relataram que foram esclarecidas suas dúvidas sobre o tema e que $97,8 \%$ participariam de nova capacitação com os mesmos palestrantes. CONCLUSÕES: A escolha da modalidade de oficinas como método pedagógico, o uso de base teórica respeitada sobre o tema, a condução por profissionais com intimidade sobre a questão do suicídio e o apoio do gestor público municipal possibilitaram que a capacitação dos profissionais da APS de São Bento do Sul/SC fosse avaliada de modo positivo pelos participantes. Contudo, somente as análises dos dados de mortalidade relacionados as causas auto infligidas do Sistema de Informação de Mortalidade (SIM), e das notificações de tentativa de suicídio e de lesões autoprovocadas do Sistema de Informações de Agravos de Notificação (SINAN) permitirão a avaliação da efetividade das ações no perfil de morbimortalidade da população de São Bento do Sul/SC.

Palavras-Chave: Atenção Primária à Saúde. Suicídio. Educação Permanente.

\section{REFERÊNCIAS}

CALIXTO FILHO, M.; ZERBINI, T. Epidemiologia do suicídio no Brasil entre os anos de 2000 e 2010. Saúde, Ética \& Justiça, v. 21, n. 2, p. 45-51, 2017.

BAGGIO, L.; PALAZZO, L. S.; AERTS, D. R. G. C. Planejamento suicida entre adolescentes escolares: prevalência e fatores associados. Cad. Saúde Pública, Rio de Janeiro, v. 25, n. 1, p. 142-150, jan. 2009.

BORGES, V. R.; WERLANG, B. S. G. Estudo de ideação suicida em adolescentes de 15 a 19 anos. Estud. psicol. Natal, v. 11, n. 3, p. 345-351, Dec. 2006. 
ORGANIZAÇÃO MUNDIAL DE SAÚDE (OMS). Prevenção do suicídio: um manual para profissionais da saúde em atenção primária [Internet]. Genebra; 2000.

Disponível em: <http://www.who.int/mental_health/prevention/suicide/ en/suicideprev_phc_port.pdf>. Acesso em: 21 jul. 2017.

ROXO BORGES, Vivian; GUEVARA WERLANG, Blanca Susana. Estudo de ideação suicida em adolescentes de 15 a 19 anos. Estudos de Psicologia, v. 11, n. 3, 2006.

Resumo recebido em: 11/12/2017

Resumo aprovado em: 17/12/2017

Resumo publicado em: 20/12/2017 